\title{
Cough, CTCAE
}

National Cancer Institute

\section{Source}

National Cancer Institute. Cough, CT CAE. NCI Thesaurus. Code C58028.

A disorder characterized by sudden, often repetitive, spasmodic contraction of the thoracic cavity, resulting in violent release of air from the lungs and usually accompanied by a distinctive sound. 